\title{
Gender differences after lumbar sequestrectomy: a prospective clinical trial using quantitative sensory testing
}

\author{
Anja Tschugg ${ }^{1} \cdot$ Wolfgang N. Löscher $^{2} \cdot$ Sara Lener $^{1} \cdot$ Matthias Wildauer $^{3} \cdot$ \\ Sebastian Hartmann ${ }^{1} \cdot$ Sabrina Neururer $^{4} \cdot$ Claudius Thomé $^{1}$
}

Received: 19 February 2016/Revised: 17 October 2016/Accepted: 17 November 2016/Published online: 21 December 2016

(c) The Author(s) 2016. This article is published with open access at Springerlink.com

\begin{abstract}
Background Quantitative sensory testing (QST) gained popularity to evaluate the time course of recovery in sensory dysfunction and the results of different treatment options. Concerning sex differences in lumbar spine surgery, female gender seems to play a major role as a negative prognostic factor in different spinal disorders. For this purpose, we hypothesised that there are also comparable differences in pain patterns in men and women after lumbar sequestrectomy using QST.

Methods We applied the QST protocol of the German Research Network on Neuropathic Pain in 53 patients (21 women and 32 men) with a single lumbar disc herniation confirmed on MRI treated by a lumbar sequestrectomy. Further evaluation included a detailed medical history, a physical examination, and various questionnaires: BeckDepression-Inventory, Oswestry Disability Index, Core Outcome Measure Index, painDETECT-Questionnaire and EQ-5D thermometer.

Results Our analyses showed lower heat thresholds in females preoperatively, that adjusted to that of males 1 week postoperatively. Pressure pain thresholds were lower in women as well, but differed between genders throughout the
\end{abstract}

Anja Tschugg

anja.tschugg@i-med.ac.at

1 Departmen of Neurosurgery, Innsbruck Medical University, Anichstr. 35, 6020 Innsbruck, Austria

2 Department of Neurology, Innsbruck Medical University, Innsbruck, Austria

3 Department of Neuroradiology, Innsbruck Medical University, Innsbruck, Austria

4 Department of Medical Statistics and Health Economics, Innsbruck Medical University, Innsbruck, Austria study. Vibration perception deficits resolve earlier in female than in male patients. Both, women and men, had an excellent overall improvement, postoperatively.

Conclusion Our results clearly revealed pre- and postoperative differences in pain perception between genders. These differences have to be taken into account in the evaluation of outcome between genders. Therefore, QST seems to be a good method to evaluate the time course of recovery after surgery.

Keywords Lumbar sequestrectomy - Quantitative sensory testing · Gender differences in spine surgery - Lumbar disc herniation - Lumbar radiculopathy

\section{Introduction}

Lumbar disc herniation with radiculopathy is a clinical diagnosis defined by the presence of sensory and motor deficits and complaints caused by mechanical compression of the corresponding lumbar nerve root. A minority of patients affected require surgical treatment, especially in the presence of neurological deficits [1]. The main surgical technique is represented by lumbar sequestrectomy [2].

Various options of screening tools for measuring outcome after spinal surgery are available [3, 4]. Quantitative sensory testing (QST) gained popularity in clinical practice and research, especially to evaluate the time course of recovery in sensory dysfunction and the results of different treatment options. Although a huge number of studies measuring the outcome after surgical treatment have been published, there appears to have been little interest in gender aspects [5-7]. Concerning sex differences in lumbar spine surgery, female gender seems to play a major role as a negative prognostic factor in different spinal disorders 
[4, 8-12]. Besides a variety of mechanisms that have been proposed to account for these sex-related differences, pain seems to be also influenced by differences in hypothalamic-pituitary-adenocortical responses [13].

For this purpose, we hypothesised that there are also comparable differences in pain patterns in men and women after lumbar sequestrectomy using QST. Additionally, an assessment of the literature was performed matching all questions and answers of this study with the current available data in literature.

\section{Materials and methods}

\section{Subjects}

The study was purely observational. Pain management was not delayed or altered by participation in this study. All subjects gave their informed consent. The study was approved by the Local Ethics Committee of the Medical University of Innsbruck. Consecutive patients were considered for inclusion if they had a single-level disc herniation confirmed on magnetic resonance imaging (MRI) and a medically refractory radiating pain and/or motor deficits in the corresponding nerve root distribution area of L3 to S1. All patients had an indication for sequestrectomy according to the guidelines of the German Society of Neurosurgery and the German Society of Orthopaedics and Orthopaedic Surgery. No previous back surgery had been performed in any of the patients. None of the included patients had a history of peripheral nervous system disorders. Neither metabolic nor toxic damage of the peripheral nerves was revealed. In female patients, no adjustment for menstrual phase was made at the time of testing. The study group consisted of 21 women and 32 men.

\section{Magnetic resonance imaging}

Preoperative magnetic resonance imaging (MRI) of the lumbar spine was performed in a standardised fashion on a 3.0-T MRI scanner (Siemens, Verio). The protocols included sagittal T1-TSE and T2-TSE, and axial T1-TSE and PD/T2-TSE. Each MRI was examined for the evidence of disc degeneration (Pfirrmann degeneration grade) and degenerative changes of the intervertebral endplates (Modic changes) by an independent neuroradiologist, blinded to the clinical signs and symptoms [14, 15].

\section{Questionnaires, medical history and clinical examination}

The prospectively planned evaluation included a detailed medical history, a physical examination, and various questionnaires. All data were recorded the day before surgery, within 1 week, 6 and 12 months after surgery. The visual analog scale (VAS) was additionally evaluated on the first, second and third postoperative day. The Beck Depression Inventory (BDI) was used for measuring the severity of depression and responsiveness to treatment [16]. To identify neuropathic pain components, the painDETECT-questionnaire (PD-Q) was performed [17]. The degree of disability and the patient's satisfaction was assessed with the Oswestry Disability Index (ODI) [18] and the Core Outcome Measure Index (COMI) [19]. Furthermore, EQ-5D thermometer was used to assess the quality-adjusted health status from 1 to 100 (best) [20]. Neurological status and the quality and quantity of current pain medication in accordance to the WHO guidelines for pain treatment, including nerve root and facet joint injections, were documented.

\section{Quantitative sensory testing (QST)}

The QST was performed pre- and postoperatively by a single investigator. The thermal tests were performed using a Sensory Analyzer TSA-II (Medoc, Israel). Cold and warm detection thresholds were measured first (CDT, WDT), then cold pain and heat pain thresholds (CPT, HPT). The mechanical detection threshold (MDT) was measured with a standardised set of modified von Frey hairs (Somedic, Sweden) that exert forces upon bending between 0.25 and $512 \mathrm{mN}$. The vibration detection threshold (VDT) was performed with a Rydel-Seifer tuning fork (64 Hz, 8/8 scale). The mechanical pain threshold (MPT) was measured by a custom made pinprick set with forces from 8 to $512 \mathrm{mN}$. Mechanical pain sensitivity (MPS) was assessed using the same pinprick stimuli to obtain a stimulus response function for pinprick evoked pain. Subjects were asked to give a pain rating for each stimulus on a 0-10 numerical rating scale (NRS "0" indicating "no pain" and "10" indicating the "most intense pain imaginable"). A pressure gauge device (FDK 20, Wagner Instruments, USA) was used to measure the pressure pain threshold (PPT) [21, 22].

\section{Surgical procedures}

Surgery was performed after induction of general endotracheal anaesthesia and with the assistance of an operating microscope (Pentero, Carl Zeiss Co.) while the patient was in a prone position, by two surgeons in a standardised manner. The spinal canal harbouring the sequestrated disc material was exposed by performing a minimal inter-laminar fenestration in cases of non-dislocated or caudally herniated disks. In cases of cranially herniated disks, a translaminar approach was undertaken. Based on results of 
previous trials only the herniated material was removed and the herniated space was not entered, if at all possible [2]. Surgery related complications and postoperative complications like re-operations, recurrent disc herniations, infection or hematoma were recorded.

\section{Statistical analysis}

All patients with a complete preliminary examination were considered for inclusion into the study population. All values were expressed as mean $\pm \mathrm{SD}$. The KolmogorovSmirnov test was used for testing normal distribution. The unpaired Student's $t$ test, Mann-Whitney $U$ test and Fisher's exact test were used to analyse differences in clinical and demographic characteristics and in clinical outcome variables. A $p$ value $<0.05$ was considered statistically significant. All statistical evaluations were performed with SPSS Version 21.0 (IBM Corp. Released 2012. IBM SPSS Statistics for Windows, Version 21.0, NY: IBM Corp.). Figures were designed using GraphPad Prism (version 5.0 for Mac OS X, GraphPad Software, La Jolla California USA, http://www.graphpad.com).

\section{Results}

\section{Loss-of-follow-up}

56 patients that met the initial in- and exclusion criteria were prospectively included in the trial. Three patients withdrew the informed consent. Participants with intraoperative nerve root damage or postoperative complications (e.g. recurrent disc herniations) were excluded from the study as these factors would have influenced the outcome data. Therefore, the overall rate of 6 and 12 months follow-up was $80.4 \%$ and of 12 months was $69.7 \%$, respectively. The most common reason for exclusion was a recurrent disc herniation in $16 \%$. The drop out rate was three times higher for men than for women. In all of these patients, a second sequestrectomy was performed. Two men developed a second reherniation and underwent spinal fusion one year thereafter. Loss of follow-up of $30 \%$ at one year creates a significant void in the results and could have potentially lead to a type 1 error.

\section{Population characteristics, medical history and intra-operative parameters}

The preoperative demographic details are presented in Table 1. There were no significant intergroup differences in the preoperative demographic data. In twelve patients, periradicular steroid application was applied within 30-90 days preoperatively for pain management. 66\% of female and $62 \%$ of male patients took analgesics on a regular basis before surgery (Table 2). Except for one man who took $150 \mathrm{mg}$ pregabalin daily, no permanent pain medication was used; none of the patients received a nerve root or facet joint injection, postoperatively. There was no difference in total operation time in minutes (73.7 $\mathrm{min} . \pm 26.0$ for women vs. $73.6 \mathrm{~min} . \pm 32.2$ for men) or intra-operative radiation time in seconds between genders (5.0 s. \pm 8.4 vs. $5.0 \mathrm{~s} . \pm 6.6)$, respectively. The area dose product in Gy $\mathrm{cm} 2$ was lower in female than in male patients $(29.3 \pm 22.1$ vs. $54.4 \pm 34.8, p<0.05)$. As preoperative steroid injections in 12 patients could have potentially influenced the outcome after surgery, statistical analyses were performed between the two groups. Postoperatively, there were no significant differences, neither in the QST data nor in the clinical outcome scores.

\section{Quantitative sensory testing}

The results of the QST thresholds are presented in Fig. 1. HPT and PPT were preoperatively found to be lower in female than in male patients: HPT $46.1{ }^{\circ} \mathrm{C} \pm 8.0$ and PPT $5.6 \mathrm{~kg} \pm 2.7$ in females vs. HPT $48.8^{\circ} \mathrm{C} \pm 2.1$ and PPT $7.5 \mathrm{~kg} \pm 2.6$ in males $(p<0.05)$. ALL did only occur in females and disappeared after one year follow-up, a significant gender difference was not found. VDT reached a significant difference at 1 week follow-up, $6.7 \mathrm{~Hz} \pm 1.3$ for women and $5.6 \mathrm{~Hz} \pm 2.2$ for men, respectively $(p<0.05)$. MDT differed significantly 12 months postoperative between genders: $1.8 \mathrm{mN} \pm 1.8$ in female, $15.5 \mathrm{mN} \pm 29.5$ in male participants $(p<0.05)$. Pre- and postoperative thermal detection thresholds (CDT and WDT) and MDT tend to be lower in women than in men $(p>0.05)$. PPT differed significantly between genders at 1 week, 6 and 12 months follow-up period $(p<0.05)$.

\section{Questionnaire}

Leg pain on VAS was rated insignificantly higher in female than in male patients, whereas low back pain revealed to be higher in male patients $(p>0.05)$. At admission the mean overall VAS was detected $5.8 \pm 2.0$ in women and $4.4 \pm 2.6$ in men $(p<0.05)$, respectively (see Fig. 2). Analysis of BDI data demonstrated no significant gender differences, but there was a trend towards higher depression scores in females. ODI indicated a trend to lower disability in women preoperatively, but adjusted the first week after surgery $(p>0.05)$. There was also a trend in PD-Q that indicated higher neuropathic pain components, preoperatively (19.3 \pm 5.7 vs. $16.3 \pm 6.5 ; p>0.05)$. Additionally, women showed an insignificantly lower quality of health in EQ-5D thermometer preoperatively, 1 week and 6 months postoperatively $(p>0.05)$. For more details see Table 3 . 
Table 1 Demographic, pain and radiological characteristics of female and male patients with lumbar disc herniation

\begin{tabular}{|c|c|c|}
\hline Demographic characteristics & 우 & $\hat{\jmath}$ \\
\hline Mean age, years (SD) & $43.2( \pm 2)$ & $45.5( \pm 11)$ \\
\hline Mean BMI (SD) & $26.8( \pm 4)$ & $26.6( \pm 3)$ \\
\hline Smoking, $n(\%)$ & $12 / 21(57.1)$ & $17 / 32(53.1)$ \\
\hline Cigarettes per day (SD) & $6.90( \pm 7)$ & $7.76( \pm 10)$ \\
\hline \multicolumn{3}{|l|}{ Alcohol } \\
\hline None, $n(\%)$ & $8 / 21(38.1)$ & $7 / 32(21.9)$ \\
\hline Weekly, $n(\%)$ & $0 / 21(0)$ & $2 / 32(6.3)$ \\
\hline Incidentally, $n(\%)$ & $13 / 21(61.9)$ & $23 / 32(71.9)$ \\
\hline \multicolumn{3}{|l|}{ ASA score } \\
\hline $1, n(\%)$ & $13 / 21(61.9)$ & $19 / 32(59.4)$ \\
\hline $2, n(\%)$ & $8 / 21(38.1)$ & $13 / 32(40.6)$ \\
\hline \multicolumn{3}{|l|}{ Physical activity } \\
\hline None, $n(\%)$ & $6 / 21(28.6)$ & $8 / 32(25)$ \\
\hline Daily, $n(\%)$ & $5 / 21(23.8)$ & $11 / 32(34.4)$ \\
\hline Weekly, $n(\%)$ & $5 / 21(23.8)$ & 6/32 (18.8) \\
\hline Incidentally, $n(\%)$ & $5 / 21(23.8)$ & $7 / 32(21.9)$ \\
\hline Nerve root injection with steroid, $n(\%)$ & 4/21 (19) & $8 / 32(25)$ \\
\hline Pain Characteristics & q & $\hat{0}$ \\
\hline Mean duration of pain in days (SD) & $136( \pm 190)$ & $180( \pm 301)$ \\
\hline \multicolumn{3}{|l|}{ Leg-raising test } \\
\hline Negative, $n(\%)$ & $6 / 21(28.6)$ & $5 / 32(12.5)$ \\
\hline Positive, $n(\%)$ & $15 / 21(71.4)$ & $27 / 32(84.4)$ \\
\hline \multicolumn{3}{|l|}{ Radicular pain } \\
\hline $\mathrm{L} 3, n(\%)$ & $0 / 21(0)$ & $5 / 32(12.5)$ \\
\hline $\mathrm{L} 4, n(\%)$ & $3 / 21(14.3)$ & $2 / 32(6.3)$ \\
\hline $\mathrm{L} 5, n(\%)$ & $7 / 21(33.3)$ & $14 / 32(43.8)$ \\
\hline $\mathrm{S} 1, n(\%)$ & $11 / 21(52.4)$ & $14 / 32(43.8)$ \\
\hline Radiological classification & q & $\hat{o}$ \\
\hline \multicolumn{3}{|l|}{ Modic changes } \\
\hline None, $n(\%)$ & 4/21 (19) & $15 / 32(46.9)$ \\
\hline Type $1, n(\%)$ & $1 / 21(4.8)$ & $2 / 32(6.3)$ \\
\hline Type $2, n(\%)$ & $14 / 21(66.7)$ & $15 / 32(46.9)$ \\
\hline Type $3, n(\%)$ & $2 / 21(9.5)$ & $0 / 32(0)$ \\
\hline \multicolumn{3}{|l|}{ Pfirrmann grade } \\
\hline $3, n(\%)$ & $1 / 21(4.7)$ & 9/31 (28.8) \\
\hline $4, n(\%)$ & 17/21 (80.9) & $16 / 31(51.2)$ \\
\hline $5, n(\%)$ & $3 / 21(14.2)$ & 6/31 (19.2) \\
\hline Disc lesion size $(\mathrm{mm})$ & $8.5 \pm 2$ & $8.5 \pm 4$ \\
\hline
\end{tabular}

ASA American Society of Anesthesiology, BMI body mass index, $n$ number of patients, $S D$ standard deviation

$\hat{o}$ male, o f female

\section{Discussion}

The authors present the results of the first prospective clinical trial comparing gender differences in patients after lumbar sequestrectomy using QST. The analyses showed
Table 2 Preoperative pain medication of female and male patients with lumbar disc herniation

\begin{tabular}{lll}
\hline & $\begin{array}{l}+ \\
n=21\end{array}$ & $\begin{array}{l}\hat{0} \\
n=32\end{array}$ \\
\hline No medication, $n(\%)$ & $7 / 21(33.3)$ & $12 / 32(37.5)$ \\
Non-opoid analgetics, $n(\%)$ & $11 / 21(52.3)$ & $18 / 32(56.2)$ \\
Naproxene mg/d & 3000 & 4000 \\
Metamizol mg/d & 3500 & 8000 \\
Paracetamol mg/d & 2500 & 6500 \\
Diclofenac mg/d & 600 & 600 \\
Dexibuprofen mg/d & 2400 & 5600 \\
Weak opioid analgetics, $n(\%)$ & $4 / 21(19)$ & $6 / 32(18.8)$ \\
Tramadol mg/d & 900 & 950 \\
Strong opioid analgetics, $n(\%)$ & $3 / 21(14.3)$ & $8 / 32(25)$ \\
Oxycodon mg/d & 0 & 65 \\
Piritramid mg/d & 30 & 22.5 \\
\hline 66\% of female and $62 \%$ of male patients
\end{tabular}

$66 \%$ of female and $62 \%$ of male patients took analgesic on a regular basis before surgery

$n$ number of patients

ô male, o female

lower heat thresholds in females preoperatively, that adjusted to that of males 1 week postoperatively. Pressure pain thresholds were lower in women too, but differed between genders throughout the study. Vibration perception deficits resolved earlier in female than in male patients. Mechanical detection threshold differed significantly 12 months postoperative between genders. The overall VAS was detected higher in female than in male participants, preoperatively. Minor insignificant differences between genders persisted also postoperatively, but both sexes showed an overall improvement.

Male participants showed higher pain thresholds and tolerance. The largest effect size was found for heat and pressure pain $[11,22]$. Women were more sensitive than men for many QST parameters, consistent with prior studies $[22,23]$. Especially pressure pain was lower in females throughout the follow-up period. Pressure pain has been used widely to investigate the efficacy of therapeutic interventions for the treatment against pain and correlates well with the clinical status of pain as changes in PPT are accompanied by significant changes in VAS scores $[25,26]$. These gender differences in pain thresholds are unlikely to be due to peripheral factors such as innervation density and different central processing [24].

Although women have shown a greater sensitivity to multiple pain modalities compared to men, detection thresholds were generally independent of gender [22, 27]. As all of our patients suffered from a pre-operative sensory deficit, we suppose that mechanical perception deficits resolve earlier in female than in male participants. 

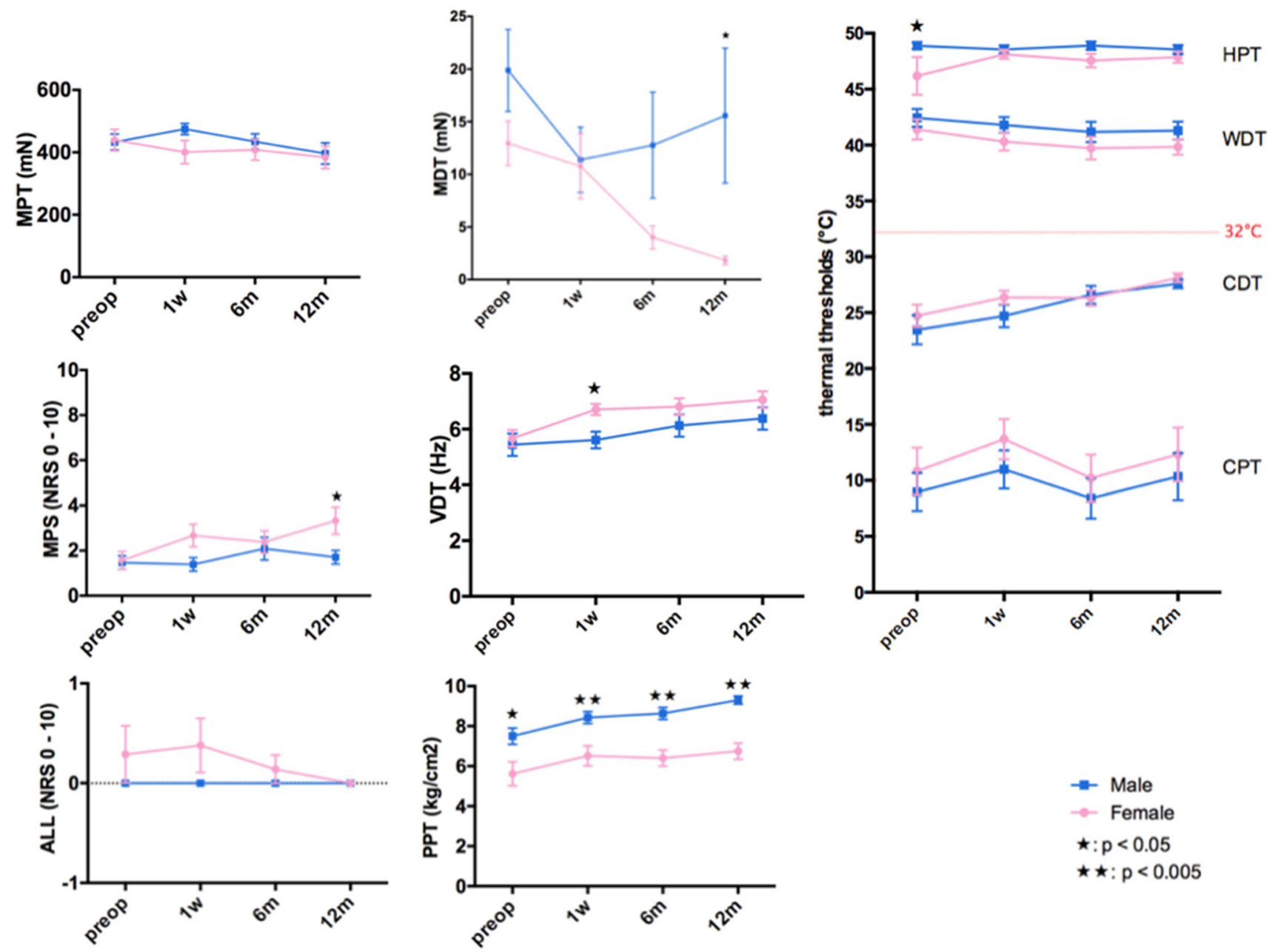

Fig. 1 Pre- and postoperative gender differences in thermal and mechanical perception and pain thresholds in patients with lumbar disc herniation. Data are presented as mean and standard error of the mean. $1 w 1$ week, $6 \mathrm{~m} 6$ months, $12 \mathrm{~m} 12$ months, $C D T$ cold detection thresholds, $W D T$ warm detection threshold, $C P T$ cold pain

threshold, $H P T$ heat pain threshold, $M P T$ mechanical pain threshold, $M D T$ mechanical detection threshold, MPS mechanical pain sensitivity, VDT vibration detection threshold, $A L L$ allodynia, $P P T$ pressure pain threshold, $* p<0.05, \quad * * p<0.005$ (statistical significant)

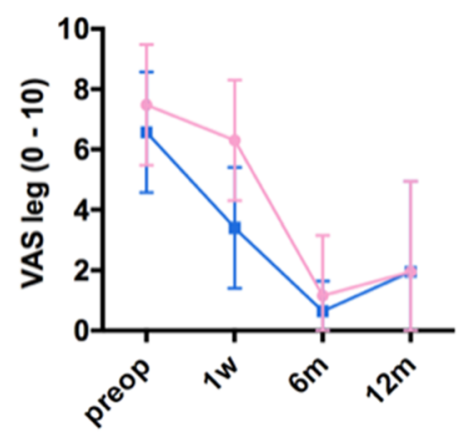

Fig. 2 Gender-specific visual analog scale (VAS) before and 1 year after surgery. General pain was rated higher in female than in male patients, whereas low back and leg pain was assumed higher in male

All outcome measures improved subsequent after sequestrectomy. According to already published data, females tend to be more disabled preoperatively, but both
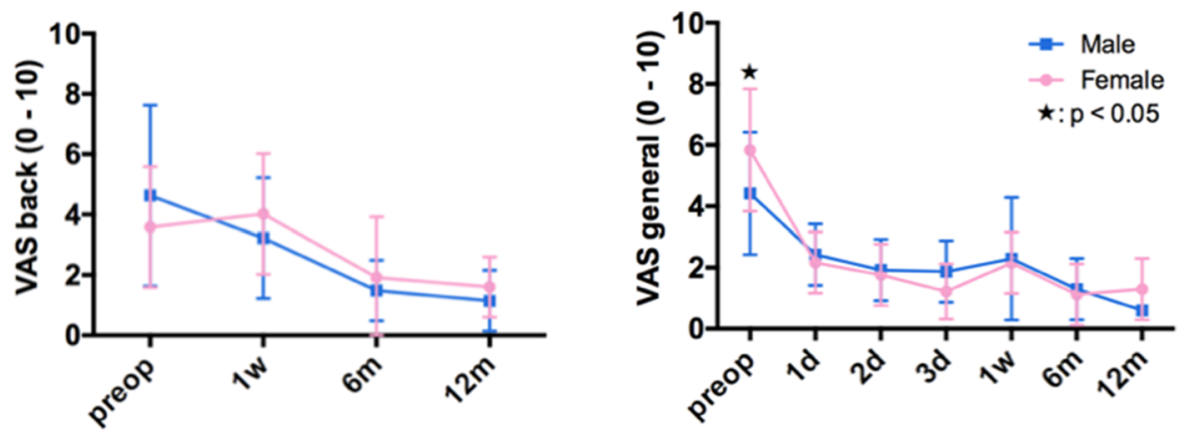

patients. $1 w 1$ week, $6 m 6$ months, $12 m 12$ months, $1 d 1$ day, $2 d 2$ days, $3 d 3$ days. Data is presented as mean and standard deviation. $* p<0.05$ (statistical significant)

sexes showed an overall improvement postoperatively [12, 28, 29]. Nevertheless, the improvement of pain and disability after lumbar spine surgery is not only associated 


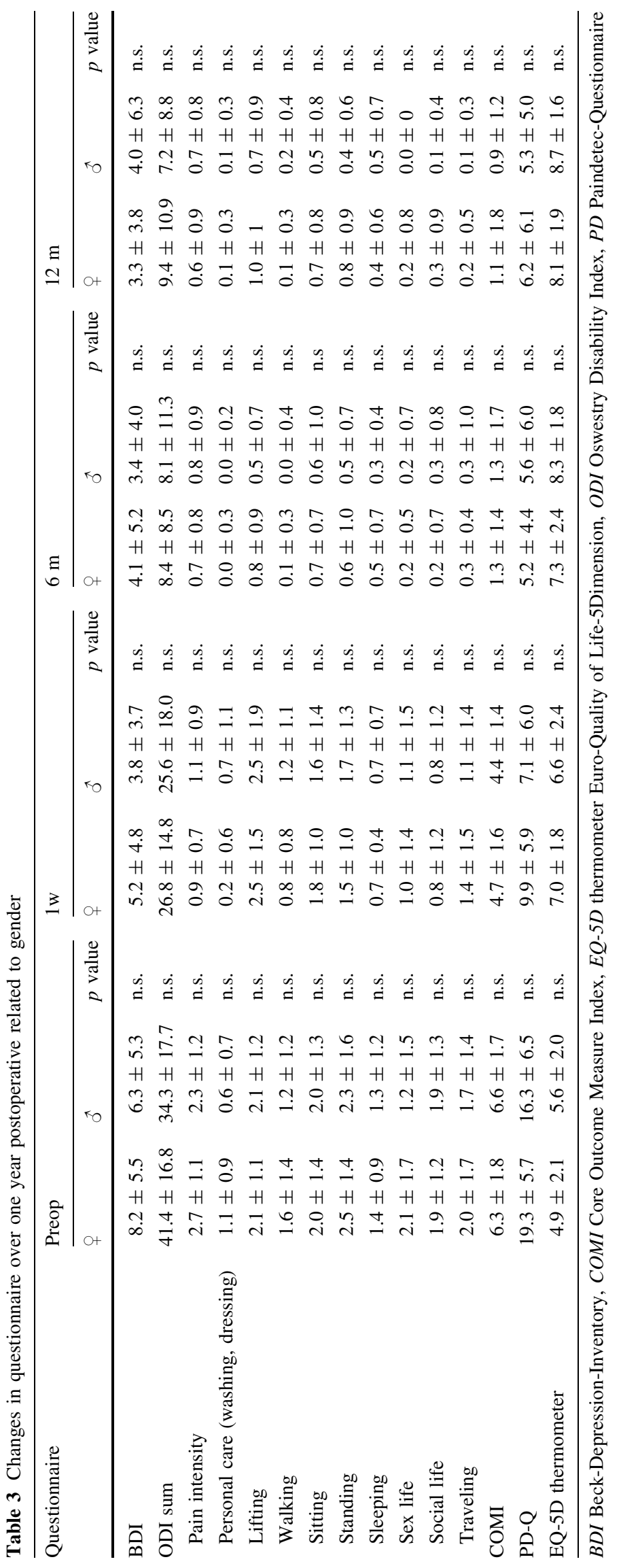


with gender, but various other factors seem to play a crucial role [30]. Therefore, valid measures are needed to predict the surgical success in patients undergoing sequestrectomy [31, 32].

In sciatica, the prevalence in men is 1.5-3 times higher compared to women [1, 9, 33, 34]. This has been conventionally explained by the fact that men tend to work in more physically demanding occupations. However, in childhood and adolescence, the situation might even be vice versa, at least when it comes to lumbar back pain. There, girls have been reported to have a higher prevalence of pain [35]. These dissimilarities on the other hand are due to hormonal differences and the onset of menstruation-related pain in women [36]. Nevertheless, disc degeneration is multifaceted, traditionally attributed to age, mechanical loading, gender, trauma, obesity and other factors impairing disc nutrition [37-41].

Attributed to the increase of minimal invasive spine surgery over the last decades, the use of fluoroscopic imaging has risen dramatically. Radiation exposure performed during surgery, although low and within established limits, remains a health concern not only among patients, but especially among surgeons [42]. Regardless of the same time of radiation exposure, female patients in our study were susceptible to a lower radiation dose than men. A possible explanation therefore is the distribution of fat tissue. Since fat tissue is usually located around the hip level in females, it does not block the view of the vertebral lumbar spine to the same extent as it does in males. Therefore, a lower radiation dose is needed [43, 44].

A limitation of our findings was the missing determination of the hormone status in female patients. Previous studies show hormonal influences on pain perception in women, regarding higher pain thresholds for mechanical and thermal pain during the follicular phase of the menstrual cycle $[36,45]$. There are a number of further limitations, such as the small sample size and some loss of follow-up. In conclusion, our results and the literature reviewed above clearly indicate that pre- and postoperative differences in pain perception between genders exist. According to our study, QST seems to be a good method to evaluate the time course of recovery after surgery.

Acknowledgements Open access funding provided by University of Innsbruck and Medical University of Innsbruck. Thanks for the imaging support to Prof. Dr. Elke Gizewski (Department of Neuroradiology, Innsbruck Medical University), to Kathi Jeller and Ulli Tripp (Department of Neurology, Innsbruck Medical University) for their overall support.

\section{Compliance with ethical standards}

Conflict of interest None of the authors has any conflict of interest in connection with the study.
Open Access This article is distributed under the terms of the Creative Commons Attribution 4.0 International License (http://crea tivecommons.org/licenses/by/4.0/), which permits unrestricted use, distribution, and reproduction in any medium, provided you give appropriate credit to the original author(s) and the source, provide a link to the Creative Commons license, and indicate if changes were made.

\section{References}

1. Weinstein JN, Lurie JD, Tosteson TD et al (2006) Surgical vs nonoperative treatment for lumbar disk herniation: the Spine Patient Outcomes Research Trial (SPORT) observational cohort. JAMA 296:2451-2459

2. Thomé C, Barth M, Scharf J, Schmiedek P (2005) Outcome after lumbar sequestrectomy compared with microdiscectomy: a prospective randomized study. J Neurosurg Spine 2:271-278

3. Mannion AF, Porchet F, Kleinstück FS, Lattig F, Jeszenszky D, Bartanusz V, Dvorak J, Grob D (2009) The quality of spine surgery from the patient's perspective: part 2. Minimal clinically important difference for improvement and deterioration as measured with the Core Outcome Measures Index. Eur Spine J 18(Suppl 3):374-379

4. Strömqvist F, Ahmad M, Hildingsson C, Jönsson B, Strömqvist B (2008) Gender differences in lumbar disc herniation surgery. Acta Orthop 79:643-649

5. Samuelsson L, Lundin A (2002) Thermal quantitative sensory testing in lumbar disc herniation. Eur Spine J 11:71-75

6. Zub LW, Szymczyk M, Pokryszko-Dragan A, Bilińska M (2013) Evaluation of pain in patients with lumbar disc surgery using VAS scale and quantitative sensory testing. Adv Clin Exp Med 22:411-419

7. Freynhagen R, Rolke R, Baron R, Tölle TR, Rutjes AK, Schu S, Treede RD (2008) Pseudoradicular and radicular low-back pain-a disease continuum rather than different entities? Answers from quantitative sensory testing. Pain 135:65-74

8. Strömqvist F, Strömqvist B, Jönsson B, Karlsson MK (2015) Gender differences in patients scheduled for lumbar disc herniation surgery: a National Register Study including 15,631 operations. Eur Spine J. doi:10.1007/s00586-015-4052-5

9. Strömqvist F, Strömqvist B, Jönsson B, Gerdhem P, Karlsson MK (2015) Lumbar disc herniation surgery in children: outcome and gender differences. Eur Spine J. doi:10.1007/s00586-015-4149-x

10. Kim HJ, Suh BG, Lee DB, Park JY, Kang KT, Chang BS, Lee CK, Yeom JS (2013) Gender difference of symptom severity in lumbar spinal stenosis: role of pain sensitivity. Pain Physician 16:E715-E723

11. Tschugg A, Löscher WN, Hartmann S, Neururer S, Wildauer M, Thomé C (2015) Gender influences radicular pain perception in patients with lumbar disc herniation. J Womens Health (Larchmt) 24:771-776

12. Pochon L, Kleinstück FS, Porchet F, Mannion AF (2016) Influence of gender on patient-oriented outcomes in spine surgery. Eur Spine J 25:235-246

13. Fillingim RB, Ness TJ (2000) Sex-related hormonal influences on pain and analgesic responses. Neurosci Biobehav Rev 24:485-501

14. Pfirrmann CW, Metzdorf A, Zanetti M, Hodler J, Boos N (2001) Magnetic resonance classification of lumbar intervertebral disc degeneration. Spine (Phila Pa 1976) 26:1873-1878

15. Modic MT, Steinberg PM, Ross JS, Masaryk TJ, Carter JR (1988) Degenerative disk disease: assessment of changes in vertebral body marrow with MR imaging. Radiology 166:193-199 
16. Smarr KL, Keefer AL (2011) Measures of depression and depressive symptoms: Beck Depression Inventory-II (BDI-II), Center for Epidemiologic Studies Depression Scale (CES-D), Geriatric Depression Scale (GDS), Hospital Anxiety and Depression Scale (HADS), and Patient Health Questionnaire-9 (PHQ-9). Arthritis Care Res (Hoboken) 63(Suppl 11):S454-S466

17. Freynhagen R, Baron R, Gockel U, Tölle TR (2006) painDETECT: a new screening questionnaire to identify neuropathic components in patients with back pain. Curr Med Res Opin 22:1911-1920

18. Fairbank JC, Couper J, Davies JB, O'Brien JP (1980) The Oswestry low back pain disability questionnaire. Physiotherapy 66:271-273

19. Mannion AF, Porchet F, Kleinstück FS, Lattig F, Jeszenszky D, Bartanusz V, Dvorak J, Grob D (2009) The quality of spine surgery from the patient's perspective. Part 1: the Core Outcome Measures Index in clinical practice. Eur Spine J 18(Suppl 3):367-373

20. Brazier J, Roberts J, Tsuchiya A, Busschbach J (2004) A comparison of the EQ-5D and SF-6D across seven patient groups. Health Econ 13:873-884

21. Rolke R, Magerl W, Campbell KA, Schalber C, Caspari S, Birklein F, Treede -D (2006) Quantitative sensory testing: a comprehensive protocol for clinical trials. Eur J Pain 10:77

22. Rolke R, Baron R, Maier C et al (2006) Quantitative sensory testing in the German Research Network on Neuropathic Pain (DFNS): standardized protocol and reference values. Pain 123:231-243

23. Castro-Sánchez AM, Matarán-Peñarrocha GA, López-Rodríguez MM, Lara-Palomo IC, Arendt-Nielsen L, Fernández-de-las-Peñas C (2012) Gender differences in pain severity, disability, depression, and widespread pressure pain sensitivity in patients with fibromyalgia syndrome without comorbid conditions. Pain Med 13:1639-1647

24. Rollman GB, Lautenbacher S (2001) Sex differences in musculoskeletal pain. Clin J Pain 17:20-24

25. Chesterton LS, Barlas P, Foster NE, Baxter G, Wright CC (2003) Gender differences in pressure pain threshold in healthy humans. Pain 101:259-266

26. Riley JL, Robinson ME, Wise EA, Myers CD, Fillingim RB (1998) Sex differences in the perception of noxious experimental stimuli: a meta-analysis. Pain 74:181-187

27. Maier C, Baron R, Tölle TR et al (2010) Quantitative sensory testing in the German Research Network on Neuropathic Pain (DFNS): somatosensory abnormalities in 1236 patients with different neuropathic pain syndromes. Pain 150:439-450

28. Häkkinen A, Kautiainen H, Järvenpää $S$, Arkela-Kautiainen M, Ylinen J (2007) Changes in the total Oswestry Index and its ten items in females and males pre- and post-surgery for lumbar disc herniation: a 1-year follow-up. Eur Spine J 16:347-352

29. Strömqvist F, Strömqvist B, Jönsson B, Karlsson MK (2015) Gender differences in patients scheduled for lumbar disc herniation surgery: a National Register Study including 15,631 operations. Eur Spine J 25:162-167
30. He J, Xiong W, Li F, Luo W, Gao S (2014) Depression influences pain and function after cervical disc arthroplasty. J Neurosurg Sci 61:39-45

31. Azimi P, Benzel EC, Montazeri A (2016) Predictive score card in lumbar disc herniation: is it reflective of patient surgical success after discectomy? PLoS One 11:e0154114

32. Azimi P, Benzel EC (2016) Cut-off value for pain sensitivity questionnaire in predicting surgical success in patients with lumbar disc herniation. PLoS One 11:e0160541

33. Frymoyer JW (1992) Lumbar disk disease: epidemiology. Instr Course Lect 1992(41):217-223

34. Peul WC, van Houwelingen HC, van den Hout WB, Brand R, Eekhof JA, Tans JT, Thomeer RT, Koes BW, Leiden-The Hague Spine Intervention Prognostic Study Group (2007) Surgery versus prolonged conservative treatment for sciatica. N Engl J Med 356:2245-2256

35. Diepenmaat AC, van der Wal MF, de Vet HC, Hirasing RA (2006) Neck/shoulder, low back, and arm pain in relation to computer use, physical activity, stress, and depression among Dutch adolescents. Pediatrics 117:412-416

36. Wedderkopp N, Andersen LB, Froberg K, Leboeuf-Yde C (2005) Back pain reporting in young girls appears to be puberty-related. BMC Musculoskelet Disord 6:52

37. Samartzis D, Karppinen J, Mok F, Fong DY, Luk KD, Cheung KM (2011) A population-based study of juvenile disc degeneration and its association with overweight and obesity, low back pain, and diminished functional status. J Bone Joint Surg Am 93:662-670

38. Cheung KM, Samartzis D, Karppinen J, Mok FP, Ho DW, Fong DY, Luk KD (2010) Intervertebral disc degeneration: new insights based on "skipped" level disc pathology. Arthritis Rheum 62:2392-2400

39. Adams MA, Freeman BJ, Morrison HP, Nelson IW, Dolan P (2000) Mechanical initiation of intervertebral disc degeneration. Spine (Phila Pa 1976) 25:1625-1636

40. Liuke M, Solovieva S, Lamminen A, Luoma K, Leino-Arjas P, Luukkonen R, Riihimäki H (2005) Disc degeneration of the lumbar spine in relation to overweight. Int $\mathrm{J}$ Obes (Lond) 29:903-908

41. Iatridis JC, MacLean JJ, Roughley PJ, Alini M (2006) Effects of mechanical loading on intervertebral disc metabolism in vivo. J Bone Joint Surg Am 88(Suppl 2):41-46

42. Chou LB, Lerner LB, Harris AH, Brandon AJ, Girod S, Butler LM (2015) Cancer prevalence among a cross-sectional survey of female orthopedic, urology, and plastic surgeons in the United States. Womens Health Issues 25:476-481

43. Stevens J, Katz EG, Huxley RR (2010) Associations between gender, age and waist circumference. Eur J Clin Nutr 64:6-15

44. Takatalo J, Karppinen J, Taimela S et al (2013) Association of abdominal obesity with lumbar disc degeneration - a magnetic resonance imaging study. PLoS ONE 8:e56244

45. Riley JL, Robinson ME, Wise EA, Price DD (1999) A metaanalytic review of pain perception across the menstrual cycle. Pain 81:225-235 